\title{
Prevention and Early Detection of Occupational Cancers - a View of Information Technology Solutions
}

\author{
Somayeh Davoodi, Reza Safdari*, Marjan Ghazisaeidi, Zeinab Mohammadzadeh, \\ Zahra Azadmanjir
}

\begin{abstract}
Thousands of people die each year from cancer due to occupational causes. To reduce cancer in workers, preventive strategies should be used in the high-risk workplace. The effective prevention of occupational cancer requires knowledge of carcinogen agents. Like other areas of healthcare industry, occupational health has been affected by information technology solutions to improve prevention, early detection, treatment and finally the efficiency and cost effectiveness of the healthcare system. Information technology solutions are thus an important issue in the healthcare field. Information about occupational cancer in information systems is important for policy makers, managers, physicians, patients and researchers; because examples that include high quality data about occupational cancer patients and occupational cancer causes are able to determine the worker groups which require special attention. As a result exposed workers who are vulnerable can undergo screening and be considered for preventive interventions.
\end{abstract}

Keywords: Cancer - occupational disease - prevention -early detection of cancer -treatment

Asian Pac J Cancer Prev, 16 (14), 5607-5611

\section{Introduction}

From the past to now, the health of people threatened by risks associated with environmental and occupational factors which can result in a wide range of diseases from allergies and non-malignant chronic diseases (Dobashi, 2012; Agrawal et al., 2014; Das, 2014) to cancers, and even gene mutations (Harris, 1970; Balamuralikrishnan et al., 2012). However, among them, cancers have a more dramatic prevalence than others. Perhaps because, occupational exposures are one of the most important factors in incidence of cancers such as bladder (Shakhssalim et al., 2010), prostate (Doolan et al., 2014), leukemia (Mosavi-Jarrahi et al., 2009; Balasubramaniam et al., 2013), non-Hodgkin lymphoma (Balasubramaniam et al., 2013), breast (Ekpanyaskul et al., 2010), stomach (Li et al., 2012), sarcomas of bone, lung, liver, thyroid, melanoma, mesothelioma, nasal cavity, paranasal sinus, larynx (2011b), and brain and other central nervous system, colon, kidney, ovarian, pancreatic, rectal, testicular cancers (Clapp et al., 2005). It is estimated that, approximately $2 \%$ to $8 \%$ of all cancers are thought to be due to occupation (Yang, 2011). Reports indicate that global provenance of neoplasms is increasing. According to GLOBOCAN latest report, there were 14.1 million new cancer cases, 8.2 million cancer deaths and 32.6 million people who living with cancer (within 5 years of diagnosis) in 2012 worldwide. Almost $57 \%$ (8 million) of new cancer cases, $65 \%$ (5.3 million) of the cancer deaths and $48 \%$ (15.6 million) of the 5-year prevalent cancer cases occurred in the less developed regions (Globocan, 2012).

In this situation, there are several challenges for occupational cancer control. For example we don't know exactly what the proportion of all of reported cancers are related to occupational cancers. This may be due to lack of accurate information about patients or the complexity of proving occupational association with cancer occurred in one patient. Other challenges are difference of occupational cancers in the implementation of prevention strategies, proper time and methods for early detection with non-occupational.

Beyond medical advances, this paper outlines the effects of IT solutions to improve and accelerate the prevention and early detection of occupational cancers.

\section{Prevention and Early Detection of Occupational Cancer}

If the WHO's global target of a $25 \%$ reduction in deaths from cancer and other non-communicable diseases in people aged 30-69 years is to be achieved by 2025 (referred to as $25 \times 25$ ), we will need not only more effective prevention (to reduce incidence) but also more effective health systems (Allemani et al., 2014). 
From the opinion of researchers focusing on strategies of primary prevention (includes awareness about cancers and risk factors such as carcinogens and avoiding exposure to them) and secondary prevention (early detection) should be a priority for countries to cancer control (Azadmanjir et al., 2015). In this regard, should be noted that, WHO's International Agency for Research on Cancer (IARC) has classified 107 agents, mixtures, and exposure situations as carcinogenic to humans (WHO, 2011). So, on the one hand, for occupational cancers control, avoiding exposure to occupational carcinogens and environmental factors is the important in primary prevention (Kye et al., 2015). According to experts, unlike lifestyle-associated cancers, occupational cancer is in principle fully avoidable through legislation leading to exposure-reducing measures (Gustavsson, 2014). Others stated that prevention and safety methods can prevent from incidence of occupational cancer (Davoodi et al.; Safdari et al., 2009).

Some countries have taken substantial steps in this regard. For instance, Directive 2004/37/EC of the European Parliament and of the Council, on the protection of workers from the risks related to exposure with carcinogens or mutagens at work sets out, a number of preventive measures to eliminate or minimize workrelated exposures to chemical carcinogens and mutagens (Brussels, 6.6.2014). In addition, the evaluation of European Union health and safety strategy 2007-2012 identified that focus on occupational cancer prevention is critical to occupational disease prevention. So the commission has adapted a new EU strategic framework for health and safety at work 2014-2020 (Brussels, 23 9.2014). WHO recommended that other strategies primary prevention, such as education, risk communication and industrial hygiene practices also considered as vital steps in global control of occupational cancers (Zare Sakhvidi et al., 2014).

On the other hand, unfortunately, the researchers announced that occupational cancers have significantly increased in recent years, basically because of their long latent period (Rim, 2013) that defined as the time interval between first exposure to a carcinogen and the point at which the risk of the cancer first increases (Rushton, 2014). Therefore, early detection must be more considered as secondary prevention.

\section{IT Solutions for Prevention of Occupational Cancer}

\section{Electronic-based Occupational Cancer Registries}

To setting preventive policies for work safety and health in the workplaces, estimating the burden of occupational cancers is essential (Straif, 2012). But, since late 1970, determine of the incidence rate of cancer due to occupational exposure was one of the important scientist challenges. (Mosavi-Jarrahi et al., 2009)

For accomplish this, authorities will need to accurate and timely information (Mohammadzadeh et al., 2013) about cancer types, the pattern of their prevalence in different geographical regions, occupational cancers with highest priority and common characteristics of involved patients to be able to identify high risk occupations, vulnerable groups and occupational hazards.

One thing is known that cancer registries are the best solution to estimate of the global cancer burden, and to gather, analyze, and publish incidence and survival data at national or regional level (Peters et al., 2015). Then, occupational cancer registry represents a fundamental tool for that purpose (Straif, 2012). The main purpose of occupational cancer registry is production of high quality information for users (Massari et al.2010). Surveillance system to reporting occupational cancers should be include the nature of the occupational hazards in the workplace, the health requirements of the work, and the health status of the working population concerned (ILO, 2013). Enough knowledge about number of workers with occupational exposures is essential. In 1995, EU in the CAREX project provides an estimation of the number of EU workers with exposure to the carcinogens (Kauppinen et al., 2000; Setton et al., 2011; Peters et al., 2015). Some other example of occupational cancer registries includes Finnish Register of Workers Exposed to Carcinogens (ASA Register) (Kauppinen et al., 2003), the Italian Information System for Recording Occupational Exposures to Carcinogens (SIREP) (Crosignani et al., 2006) and the German ODIN Register (Radek, 1998).

IARC's in the guideline about Cancer Registry Development emphasis to promote high-quality data collection and cancer registration in low-income and middle-income countries(Bray et al., 2014). Unlike paper-based registries, electronic-based registries have advantages such as updated and high quality data rapid access and retrieval and quick calculation of statistical indicators for early detection of high-risked groups (Mohammadzadeh et al., 2013).

\section{Education and self-care}

IT-based education approaches improves patient's awareness, communication between patients and providers or among patients, responsibility of health care system and providers and self-care (Demiris et al., 2008; Adams, 2010). In condition that all people use information and communications technologies such as internet and mobile networks, solutions include health portals, tele-consulting systems and health social networks can help to increase public awareness of occupational cancers and education on self-care strategies that people can apply themselves for cancer prevention. Moreover, availability of electronic workers databases can be a powerful base to develop call centers by which notify them to screening services and programs through Small Message System or E-mail.

\section{Monitoring of exposure to carcinogens}

In the other hand because the mechanism causing and influencing the carcinogenic process are still poorly understood, information technology can use for discover of the relationship among occupational exposure and occupational cancer (Kuhl and Lißner, 2015). Occupational exposure in the work place can be evaluated using various methods (Ekpanyaskul et al., 2010).For example information system should incorporate estimates of exposure levels, in order to better serve hazard surveillance, quantitative risk and burden assessment, 
and to set prevention priorities; such as WOODEX, TICAREX, Matgéné, FINJEM and CAREX Canada (Kuhl and Lißner, 2015).

\section{ITA for Early Detection Of Occupational Cancer}

\section{Bayesian-Network based systems}

Bayesian methods offer a good framework to integrate subjective judgment and available data for decision making (Vadali, 2010). At the beginning, Ramachandran and Vincent (1999) proposed applying a Bayesian probabilistic framework to expert judgment in occupational hygiene (Ramachandran and Vincent, 1999).

These systems are a type of statistical models that can compactly represent complex probability distribution; and use in order to monitor, diagnose and make predictions about diseases, all under the presence of uncertainty (Choi et al., 2011).Bayesian Systems estimates the correlation among occupational exposure rate and occupational cancer. The Bayesian imputability method provides an explicit way to quantify the causal relationship (Vandentorren et al., 2006).

\section{Expert systems}

One of the solutions for the field of occupational health professional's access to quality information about the risks and hazards associated with the disease, and other information using an online expert systems (Rhebergen et al., 2011). Expert systems are important to provide accurate information about the diagnosis and the provision of emergency medical services.(Mateo et al., 2007)

Expert systems are the most popular products of artificial intelligence that applied for solve problems by simulating the human behavior of experts; and use in different areas of medicine. For this purpose, expert opinions are collected through tools such as questionnaires, next expert's knowledge with respect to the objectives of the system translate to logical language; and then has been structured through the construction of production rules (Junkes-Cunha et al., 2014). Expert systems have benefits such as making expertise more accessible, relieving experts from routine task and providing the useful way for expert to develop and test ideas and theories.(Thomas, 1989)

The goals of expert systems for occupational diseases could include the following: a) Development of guidelines for retrospective evaluation of historical exposures in the workplace. b) Provide exposure criteria as a part of diagnostic features for compensable occupational disease c) Recognition, treatment and anticipate of occupational diseases (Burdorf and Swuste, 1999). This systems should be accessible, complete, user friendly, easy to handle, relative and applicable (Rhebergen et al., 2011).

\section{ITA for Treatment of Occupational Cancer}

\section{Electronic health record}

Because Almost 1/3 of all cancer and Most of the exposure risks for occupational cancer are preventable; (Commission, 2010; 2011a) The early detection, prevention and determine the effectiveness of treatment need access to accurate, comprehensive and timely cancer data (Mohammadzadeh and Safdari, 2014). One of the new technologies in the competitive environment of health is Electronic Health Record (EHR), which have an important role in increasing the effectiveness of health services, support decision-making and management. EHR is a main core in order to achieve best practice (Ghazisaeedi et al., 2014).

If occupational cancer EHR includes the complete and high quality data, it provides benefits such as: improve the quality, safety and efficiency of care and reduce health disparities, the involvement of patients and their families in health care, Improve care coordination, Improve Public Health and Guarantee protection for personal health information. In general, occupational cancer EHR lead to the conscious diagnosis, more-focused health plans and directed guidance to return to work (RTW) (Socias, 2013).

\section{Conceptual models}

Conceptual models are a conceptualization, simplification, or abstraction of reality. Conceptual models help to representing information for sharing, in surveillance activities (Richesson and Turley, 2003). In occupational disease a conceptual practice model can use to occupational therapy practice for activities such as assessments and intervention procedures to guide clinical practice. Conceptual models with Occupation-based do not present guidelines for application in specific populations or for specific disabilities but attempt to explain why the profession works as it does, And help to assessment the effectiveness of intervention and procedures (Leyshon, 2008; Désiron et al., 2013). Due to the chronic nature of occupational cancers use of conceptual practice models in this area can lead to early detection, treatment, and help the person return to work (RTW) (Désiron et al., 2013).

\section{Conclusion}

As most people need updated knowledge about occupational health, physicians in order to continue effective patient's treatment need to have a strong knowledge infrastructure such as information technology (Hugenholtz et al., 2009; Rhebergen et al., 2010). During the last decade, the field of occupational therapy as the most medical areas affected by technology and the use of Information and Communication Technology (ICT) (Cason, 2014). However mentioned IT provides effective solutions for health and safety promotion, better prevention and efficient treatment in the field of occupational cancer.

Continuous worldwide surveillance of cancer survival should become both an indispensable source of information for cancer patients and researchers and a stimulus for politicians to improve health policy and health-care systems. Monitoring programs and their consequent prevention strategy planning must include IT solutions for the monitoring of carcinogenic risks in the workplace or measurement of exposure levels in workers; identify the best patterns for early detection and diagnosis of occupational cancers. 


\section{References}

2011a. Environmental and occupational cancers [Online]. who. Available: http://www.who.int/mediacentre/factsheets/ fs350/en/ 2015].

2011b. List of classifications by cancer site [Online]. IARC. Available: http://monographs.iarc.fr/ENG/Classification/ Table4.pdf 2015].

Adams RJ (2010). Improving health outcomes with better patient understanding and education. Risk management and healthcare policy, $\mathbf{3}, 61$.

Agrawal S, Pearce N, Millett C, et al (2014). Occupations with an increased prevalence of self-reported asthma in Indian adults. Journal of Asthma, 51, 814-24.

Allemani C, Weir HK, Carreira H, et al (2014). Global surveillance of cancer survival 1995-2009: analysis of individual data for 25676887 patients from 279 populationbased registries in 67 countries (CONCORD-2). The Lancet.

Azadmanjir Z, Safdari R, Ghazisaeidi M (2015). From self-care for healthy people to self-management for cancer patients with cancer portals. Asian Pac J Cancer Prev, 16, 1321-5.

Balamuralikrishnan B, Balachandar V, Kumar SS, et al (2012). Evaluation of chromosomal alteration in electrical workers occupationally exposed to low frequency of electro magnetic field (EMFs) in Coimbatore population, India. Asian Pac J Cancer Prev, 13, 2961-6.

Balasubramaniam G, Saoba S, Sarade M, et al (2013). Casecontrol study of risk factors for Non-Hodgkin lymphoma in Mumbai, India. Asian Pac J Cancer Prev, 14, 775-80.

Bray F, Znaor A, Cueva P, et al (2014). Planning and developing population-based cancer registration in low-and middleincome settings. IARC, IARC Technical Publication.

Brussels (6.6.2014). Communication from the commission to the european parliament, the council, the european economic and social committee and the committee of the regions.

Burdorf A, Swuste P (1999). An expert system for the evaluation of historical asbestos exposure as diagnostic criterion in asbestos-related diseases. Annals of Occupational Hygiene, $43,57-66$.

Cason J (2014). Telehealth: A rapidly developing service delivery model for occupational therapy. International $J$ Telerehabilitation, 6, 29-36.

Choi A, Darwiche A, Zheng L, et al (2011). A Tutorial on bayesian networks for system health management. Machine Learning and Knowledge Discovery for Engineering Systems Health Management, 10, 1-29.

Clapp R, Howe G, Lefevre MJ (2005). Environmental and occupational causes of cancer. Lowell Center for Sustainable Production.

Commission E (2010). Report from the commission to the european parliament, the council, the european economic and social committee and the committee of the regions on the implementation of the trans-european energy networks in the period 2007-2009, Publications Office.

Crosignani P, Massari S, Audisio R, et al (2006). The Italian surveillance system for occupational cancers: characteristics, initial results, and future prospects. Am J Industrial Medicine, 49, 791-8.

Das PKL (2014). Occupational Exposure and pulmonary function of workers of carpet industries and sawmills, lalitpur, Nepal. Asian Journal of Medical Sciences, 5, 54-8.

Davoodi S, farshid p, Safdari R, et al Comparative study of occupational disease information system in countries United States, Finland, France and Iran in 2009. Medical Sciences Journal of Islamic Azad University. Tehran Medical Branch, 20.

Demiris G, Afrin LB, Speedie S, et al (2008). Patient-centered applications: use of information technology to promote disease management and wellness. A white paper by the AMIA knowledge in motion working group. $\mathrm{J} \mathrm{Am} \mathrm{Med}$ Informatics Association, 15, 8-13.

Désiron HA, Donceel P, de Rijk A, et al (2013). A conceptualpractice model for occupational therapy to facilitate return to work in breast cancer patients. J Occupational Rehabilitation, 23, 516-26.

Dobashi K (2012). Occupational asthma in Japan. Asia Pacific Allergy, 2, 173.

Doolan G, Benke G, Giles G (2014). An update on occupation and prostate cancer. Asian Pac J Cancer Prev, 15, 501-16.

Ekpanyaskul C, Khuhaprema T, Wiangnon S, et al (2010). Casecontrol study of occupational categories and breast cancer risk in Thailand. Asian Pac J Cancer Prev, 11, 793-7.

Ghazisaeedi M, Mohammadzadeh N, Safdari R (2014). Electronic health record (EHR) as a vehicle for successful health care best practice. Medical Archives, 68, 419-21.

Globocan. 2012. All Cancers (excluding non-melanoma skin cancer) Estimated Incidence, Mortality and Prevalence Worldwide in 2012 [Online]. Available: http://globocan. iarc.fr/Pages/fact_sheets_cancer.aspx [Accessed 6/5 2015].

Gustavsson P (2014). Strategies for Primary Prevention of Occupational Cancer. In 'Occupational Cancers', Eds Springer, 565-72

Harris RJ (1970). Cancer and the environment. International J Environmental Studies, 1, 59-65.

Hugenholtz NI, Nieuwenhuijsen K, Sluiter JK, et al (2009). Do knowledge infrastructure facilities support evidencebased practice in occupational health? An exploratory study across countries among occupational physicians enrolled on Evidence-Based Medicine courses. BMC health services research, 9, 18.

ILO (2013). National system for recording and notification of occupational diseases practical guide, Geneva, International Labour Organization.

Junkes-Cunha M, Cardozo G, Boos CF, et al (2014). Implementation of expert systems to support the functional evaluation of stand-to-sit activity. Biomedical Engineering Online, 13, 98.

Kauppinen T, Pukkala E, Saalo A, et al (2003). Exposure to chemical carcinogens and risk of cancer among Finnish laboratory workers. American J Industrial Med, 44, 343-50.

Kauppinen T, Toikkanen J, Pedersen D, et al (2000). Occupational exposure to carcinogens in the European Union. Occupational and Environmental Medicine, 57, 10-8.

Kuhl K, Lißner L. 2015. Work-related cancer [Online]. Available: http://oshwiki.eu/wiki/Work-related_cancer [Accessed 6/9 2015].

Kye S, Kwon J, Kim Y-C, et al (2015). Cancer risk factors in korean news media: a content analysis. Asian Pac J Cancer Prev, 16, 731.

Leyshon R (2008). Using the ICF as a conceptual framework to guide ergonomic intervention in occupational rehabilitation. WORK, 31, 47-62.

Li L, Ying X-J, Sun T-T, et al (2012). Overview of methodological quality of systematic reviews about gastric cancer risk and protective factors. Asian Pac J Cancer Prev, 13, 2069-79.

Massari S, Bianchi AR, Binazzi A, et al (2010) Occupational cancer registry: the ISPESL experience.

Mateo RMA, Gerardo BD, Lee J (2007). Healthcare expert system based on the group cooperation model. Intelligent Pervasive Computing, 2007. IPC. The 2007 International Conference on, 2007. IEEE, 285-8.

Mohammadzadeh N, Safdari R (2014). The intelligent clinical laboratory as a tool to increase cancer care management productivity. Asian Pac J Cancer Prev, 15, 2935-7. 
Mohammadzadeh N, Safdari R, Rahimi A (2013). Positive and negative effects of IT on cancer registries. Asian Pac J Cancer Prev, 14, 4455-7.

Mosavi-Jarrahi A, Mohagheghi MA, Kalaghchi B, et al (2009). Estimating the incidence of leukemia attributable to occupational exposure in Iran. Asian Pac J Cancer Prev, 10, 67-70.

Peters CE, Calvin BG, Hall AL, et al (2015). CAREX Canada: an enhanced model for assessing occupational carcinogen exposure. Occupational and Environmental Medicine, 72, 64-71.

Radek E (1998). The service for the organization of postexposure medical examinations: ODIN. International Archives of Occupational and Environmental Health, 71, 151-3.

Ramachandran G, Vincent JH (1999). A Bayesian approach to retrospective exposure assessment. Applied Occupational and Environmental Hygiene, 14, 547-57.

Rhebergen MD, Hulshof CT, Lenderink AF, et al (2010). An online network tool for quality information to answer questions about occupational safety and health: usability and applicability. BMC Medical Informatics and Decision Making, 10, 63.

Rhebergen MD, Lenderink AF, van Dijk FJ, et al (2011). An online expert network for high quality information on occupational safety and health: cross-sectional study of user satisfaction and impact. BMC Medical Informatics and Decision Making, 11, 72.

Richesson R, Turley JP (2003). Conceptual models: Definitions, construction, and applications in public health surveillance. J Urban Health, 80, 128.

Rim K-T (2013). Occupational cancers with chemical exposure and their prevention in Korea: a literature review. Asian Pac $J$ Cancer Prev, 14, 3379-91.

Rushton L (2014). Occupational cancer: key challenges and opportunities for change. Occupational Medicine, 64, 313-6.

Safdari R, Masouri N, Aminian O, et al (2009). Comparative study on purposes and structure of occupational diseases information system in America, Finland, French and Iran. Payavard Salamat, 2, 72-6.

Setton E, Demers P, Hystad P, et al (2011). CAREX Canadadevelopment of a national environmental carcinogen exposure surveillance tool. Epidemiology, 22, 151-2.

Shakhssalim N, Hosseini SY, Basiri A, et al (2010). Prominent bladder cancer risk factors in Iran. Asian Pac J Cancer Prev, 11, 601-6.

Straif K (2012). Estimating the burden of occupational cancer as a strategic step to prevention. Br J Cancer, 107, 1-2.

Thomas RF (1989). The Benefits of expert systems in health care. practical experiences from CATEG05-ES. In 'AIME 89', Eds Springer, 93-7

Vandentorren S, Salmi LR, Mathoulin-Pélissier S, et al (2006). Imputation of individual cancer cases to occupational causes. Scandinavian journal of work, environment \& health, 32-40.

WHO (2011). Environmental and occupational cancers [Online]. WHO. Available: http://www.who.int/mediacentre/ factsheets/fs350/en/ 2015].

Yang M (2011). A current global view of environmental and occupational cancers. J Environmental Science and Health, Part C, 29, 223-49.

Zare Sakhvidi MJ, Mirzaei Aliabadi M, Sakhvidi FZ, et al (2014). Occupational cancer risk perception in Iranian workers. Archives of environmental \& occupational health, 69, 167-71. 